\title{
Gauge Block Calibration by Interferometry
}

\section{Štěpánka Dvořáčková}

Department of Machining and Assembly, Faculty of Mechanical Engineering, Technical University of Liberec, 46117 Liberec. Czech Republic.E-mail: stepanka.dvorackova@tul.cz

\begin{abstract}
Absolute length calibration of gauge blocks traceable to the definition of meter is an important task of the national metrology institutes responsible for providing reliable length artifacts for industrial use. The length of a gauge block (henceforth, represented as GB) is defined in ISO 3650 as the distance between its one measuring face and the surface of an auxiliary platen on which the other measuring face has been wrung. Accordingly, in central length calibration of K-grade GBs using interferometry, it is required that they be wrung onto an auxiliary platen whose characteristics are the same as the measuring face of the GBs. According to this definition, the length of a GB consists of its mechanical length between two faces and the wringing film thickness. This definition is practical and reasonable in many cases because GBs are used as length standards with wringing. Also this calibration method has the advantage that the thickness of the wringing film is propagated appropriately when lower grade GBs are calibrated by comparison to higher grade GBs via a mechanical comparator. In terms of this paper is briefly described interferometry method of gauge blocks calibration. The paper was written in conjunction with Czech Metrology Institute.
\end{abstract}

Keywords: Gauge Blocks, Measurement by Interferometry, Measurement Uncertainty.

\section{Acknowledgement}

This paper is related to the investigation on the Research Project TA03010663: Advanced systems for length calibration gauge blocks and surface inspection of end standards, which are supported by the Technological Agency of the Czech Republic.

\section{References}

[1] ISO3650 1998 Geometrical Product Specifications(GPS)—Length Standards—Gauge Blocks (Geneva, Switzerland: International Organization for Standardization).

[2] 1984 Documents concerning the new definition of the meter Metrologia 19 163-77.

[3] DECKER, J. E., PEKELSKY, J. R. (1997). Uncertainty evaluation for the measurement of gauge blocks by optical interferometry, Metrologia 34 479-93.

[4] HARIHARAN, P. (1992). Basics of Interferometry, (Academic Press, Inc., New York), Chapter 8.

[5] LEWIS, A. J. (1994). Measurement of length, surface form and thermal expansion coefficient of length bars up to $1.5 \mathrm{~m}$ using multiple-wavelength phase-stepping interferometry, Meas. Sci. Technol. 5 694-703.

[6] HOWICK, E. F., WATKINS, L. R., TAN, S. M. (2003). Automation of a 1960s Hilger gauge block interferometer Metrologia 40 139-45.

[7] BIPM, IEC, IFCC, ISO, IUPAC, IUPAP and OIML 1995 Guide to the Expression of Uncertainty in Measurement (Geneva, Switzerland: International Organization for Standardization) (corrected and reprinted).

[8] BONSCH, G. (1998). Gauge blocks as length standards measured by interferometry or comparison: length definition, traceability chain, and limitations, Proc. SPIE 3477 199-210.

[9] DOIRON, T. D., EVERETT, D., FAUST, B. S., STANFIELD, E. S. STOUP, J. R. (1998). Case against optical gauge block metrology, Proc. SPIE 3477 188-98.

[10]DOIRON, T. (2008). Gauge blocks—a zombie technology, J. Res. Natl Inst. Stand. Technol. 113 175-84.

[11]HUGHES, E. B. (1993). Measurement of the linear thermal expansion coefficient of gauge blocks by interferometry, Proc. SPIE 2088 179-89. 